\title{
RADICALIZACIÓN MEDIÁTICA Y ABUSO DEL DERECHO EN LA DOCTRINA DEL TRIBUNAL EUROPEO DE DERECHOS HUMANOS
}

\author{
Radicalization of the Media and Abuse of the law in the \\ Doctrine of the European Court of Human Rights
}

\author{
David Martín Herrera ${ }^{1}$ \\ Profesor de Derecho Constitucional \\ Departamento de Servicios Sociales y Fundamento Histórico-Jurídicos \\ Universidad Nacional de Educación a Distancia
}

http://dx.doi.org/10.18543/ed-68(1)-2020pp397-424

Recibido: 02.04.2020

Aceptado: 12.06 .2020

\section{Resumen}

El Derecho de ser informado y de informar ha experimentado una auténtica revolución en cuanto a lo que se refiere al actual inmenso elenco de posibilidades. Si la liberación de los servicios de la información experimentó un paso decisivo con la apertura de la oferta informativa, la irrupción de Internet, y su inabarcable inmensidad de fuentes de información, ha terminado por sacralizar aquella tesis de Galeano en la que aseguraba que cada vez son más los que tienen el derecho de escuchar y de mirar, pero cada vez son menos los que tienen el privilegio de informar, opinar y crear.

Este tipo de Derecho sui generis parece haber terminado transformando en los últimos años el Derecho fundamental de acceso a la información, y a informar, en una dictadura de la palabra y la imagen única que, este autor, consideraba aún más devastadora que aquella surgida del modelo del partido único.

No solo por los riesgos que implica la divulgación de la falsedad; también por imponer un modo de vida que tiene por ciudadano ejemplar aquel consumidor dócil

1 Trabajo desarrollado bajo el proyecto: «Partidos políticos: origen, función y revisión de su estatuto constitucional (PAPOFRE)», DER2017-84733-R. 
y el espectador pasivo que parece haber sido moldeado al capricho del modelo de la sociedad de la información comercial. ${ }^{2}$

Un buen ejemplo de ello lo podemos encontrar en la gestión mediática de la crisis sanitaria en torno al COVID-19. Una epidemia con orígenes remotos pero que ha terminado por propagarse infinitamente más rápido de lo que ha pretendido la contención mediática con el fin de tranquilizar a la ciudadanía y tratar de asegurar la continuidad de los mercados. El resultado de esa maniobra ha propiciado el desastre y las dramáticas consecuencias que todos ahora sufrimos.

\section{Palabras clave}

Libertad de información, public watchdog, chilling effect, abuso del derecho, propaganda.

\section{Abstract}

The Right to be informed and to inform has undergone a real revolution in what refers to the current vast range of possibilities. The liberation of the information services underwent a decisive step with the opening of the informative offer, but the arrival of the Internet, and its immeasurable immensity of information sources, has ended up forging Galeano's thesis in which he assured that more and more people have the right to listen and look, but fewer and fewer people have the privilege to report, think and create.

This type of law sui generis seems to have ended up transforming in recent years the fundamental right of access to information and to inform, into a dictatorship of the word and the unique image that Galeano considered even more devastating than that arising from a single-party system.

Not only because of the risks involved in spreading falsehood; also for imposing a way of life that states as an exemplary citizen a docile consumer and a passive spectator who seems to have been molded at the whim of the commercial information society model.

A good example of this is the media management of the health crisis around COVID-19. An epidemic with remote origins but which has ended up spreading infinitely more quickly than the media had intended in order to reassure citizens and try to ensure the continuity of the markets. All this has generated the disaster and the dramatic consequences that we are all suffering.

\section{Key Words}

Freedom of information, public watchdog, chilling effect, abuse of rights, propaganda.

2 «Los cuatro puntos cardinales del globo, y la propia Europa, han sido conquistados por ese moral cóctel de sangre, valium y publicidad que dicta las pautas de la televisión privada». Vid. GALEANO, E., La comunicación desigual, Conferencia en la Unidad Xochimilco, México, 1995. 


\begin{abstract}
SuMARIO: I. CAPACIDAD DE INFORMAR Y CAUTIVAR DE LAS FUENTES MEDIÁTICAS. 1. Liberación vs. desprotección. Las diversas caras de la información. 2. La prensa como vehículo transmisor de ideas, denuncia de atrocidades y de controversias en la perspectiva de los tribunales. II. El Tribunal Europeo de Derechos Humanos y la RadicaLización mediática. 1. Sürek vs. Turquía, de 8 de julio de 1999. 2. Asunto Dink vs. Turquía, de 14 de septiembre de 2010. III. CoNCLUSIÓN. BIBLIOGRAFIA.
\end{abstract}

\title{
I. CAPACIDAD DE INFORMAR Y CAUTIVAR DE LAS FUENTES MEDIÁTICAS
}

El poder con el que cualquier canal de comunicación se emite ha sido siempre un factor decisivo a la hora de procurar llegar a un amplio público. Desde la espera por el turno en el mítico Speaker's corner, hasta la lucha por el reparto de licencias televisivas, la capacidad de llegar a la audiencia y poder influir así sobre la masa es determinante.

En su ensayo sobre la libertad de expresión, Barendt, se preguntaba si los tribunales debían de conferir mayor o menor libertad a la prensa con respecto a la libertad de expresión. Partiendo de esta aproximación si confeccionamos una escala de capacidades informativas no resulta sencillo determinar dónde debieran de posicionarse los libros, las revistas los periódicos... ni cuán fuerte ha de ser la inmunidad del periodista ante la revelación de las fuentes y de la propia prensa ante un eventual registro policial. ${ }^{3}$

Estas cuestiones, sin lugar a dudas, han suscitado innumerables conflictos judiciales y han ido dibujando el rol fundamental de los medios de comunicación.

Por la importancia de los medios y su capacidad de seducción informativa Barendt plantea que quizá fuera preciso considerar la pertinencia de frenar la inmunidad absoluta de los medios de comunicación masiva cuando existan buenas razones para investigar su actividad. ${ }^{4}$

En sentido contrario, Baker advierte de que cualquier investigación gubernamental supervisora de los medios de comunicación podría dañar seriamente la función revisora de la prensa. ${ }^{5}$

Pero lo cierto es que, ambos planteamientos, no están ausentes de justificación y perfilan la tímida y controvertida delimitación entre el discurso protegido y el extralimitado. La ausencia de nitidez gráfica del límite a la

3 Vid. BARENDT, E., Freedom of Speech..., op. cit., pp. 67-77.

4 Ibídem, p. 77.

5 Vid. BAKER, C. E., Human Liberty and Freedom of Speech..., op. cit., p. 247. 
legalidad informadora continúa dando paso a formas de represión y silenciamiento legal desde las posiciones dominantes del poder.

\section{Liberación vs. desprotección. Las diversas caras de la información}

La descomunal capacidad de los medios de comunicación masiva ha constatado, una y otra vez, qué, dándose los condicionantes idóneos, la amplitud expansiva de la información puede propiciar un efecto mariposa social con la fuerza suficiente de generar un sistema dinámico capaz de desvirtuar las fuentes predominantes y cercanas a la posición del poder.

Por ello cualquier injerencia sobre los servicios de información debe de cumplir unas estrictas garantías sino se desea precipitar a la sociedad al abismo de la censura y la perpetuación del poder monolítico.

Desproteger las comunicaciones, que no constituyen trasmisión de ideas, impide que el Marketplace of ideas funcione como tal; carece de apoyo y termina pecando de ingenuidad. Tal y cómo advierte De Luca en referencia a la prevención de la destrucción externa e interna del mercado libre de las ideas a través de expresiones antidemocráticas, de odio y discriminatorias. ${ }^{6}$

Con rigor, acentúa este autor que los canales habilitados a los ciudadanos para comunicar y recibir información quedan limitados a los medios de comunicación masivos que únicamente emiten las comunicaciones que corresponden a sus únicos intereses. Y por ello se torna demagógico enjuiciar expresiones que no logran conmover un ápice el discurso de la mayoría dominante y de los medios de comunicación a los que no pueden llegar a desafiar.

...se transforma en funcional al sistema de conformación de los mensajes del grupo dominante que admiten que unos pocos disidentes sin poder alguno digan cualquier cosa porque, en realidad, no ponen en peligro el sistema vigente. Terminan por dotar de una fundamentación simbólica a la libertad de expresión, porque en realidad no se discute la libertad de comunicar aquellas ideas peligrosas para el sistema. Las ideas inofensivas son mostradas como simpáticas o aborrecibles, pero siempre con base en su inofensividad para quien tiene que juzgarlas. ${ }^{7}$

Resulta así evidente la importancia de la comunicación en la formación de una opinión pública plural y libre de obstáculos. La misión de la media no inicia ni concluye en la mera trasmisión de ideas ante la sociedad. Su función es mucho más elocuente y es del todo crucial para la formación de las sociedades democráticas. Su función, siguiendo a Fiss, demanda, entre otros, cuestiones

${ }^{6}$ Vid. DE LUCA, A. J., Libertad de prensa y delitos contra el honor: delitos contra el honor cometidos a través de la prensa, Buenos Aires, Ad-Hoc, 2006, pp. 234-5.

7 Ibídem, p. 235. 
tan relevantes como el acercamiento entre los diversos candidatos en las campañas electorales, sus políticas y sus prácticas de gobierno; para que los ciudadanos puedan conocer y determinar la idoneidad de sus futuros representantes. Tal misión ha venido siendo desempeñada, de forma tradicional, por la prensa y la televisión, quienes, con el fin de cumplir con esas responsabilidades democráticas, precisan de un grado de autonomía respecto del Estado. ${ }^{8}$

Sin embargo, el referido grado de autonomía puede patentarse necesario desde un punto de vista objetivo e incluso ideológico; pero, funcionalmente, su evidencia enfatiza aquella frase del expresidente Rafael Correa quién, por todos, afirmara que, «desde que se inventó la imprenta, la libertad de prensa es la voluntad del dueño de la imprenta».

Esta teorización de la independencia de la libertad de prensa ya fue argüida por Marcuse, quien aseguraba que mediante la concentración del poder económico y político se bloquea el disenso efectivo que debiera surgir libremente de la formación de opiniones, de la información, de la comunicación, de la libertad de expresión y de reunión. «Bajo el dominio de los medios de masa monopolistas -que son a su vez meros instrumentos del poder económico y político- se crea una mentalidad para la cual lo justo y lo injusto, lo verdadero y lo falso se definen de antemano en todos los puntos en que afectan el interés vital de la sociedad». ${ }^{9}$

Dominio mediático que incluso fue referido por quien hiciera de la propaganda el icono clave de su régimen. Así, el propio Hitler, antes de llegar al poder denunció que desde Estados Unidos, los judíos, a través del control bursátil de la prensa, comenzaron «una campaña propagandística sin precedente. Se construyó una gigantesca organización para la mentira periodística. [...] se incitó a veintiséis pueblos, uno contra otro, mediante esta prensa que está exclusivamente en poder de uno...». ${ }^{10}$

${ }^{8}$ Vid. FISS, O., The Irony of Free Speech..., op. cit., p. 71.

9 Confirma así la teoría de la retórica como medio de manejo de las masas. Una forma por la cual, a través del lenguaje, se trata de bloquear el disenso e identificar todo aquello que no es del establishment. Lo ejemplifica en la tesis: «trabajamos para la paz; antítesis: nos preparamos para la guerra (o incluso hacemos la guerra); unificación de los opuestos: prepararse para la guerra es trabajar para la paz. La paz se redefine como algo que incluye necesariamente, a raíz como algo que incluye necesariamente, a raíz de la situación reinante, la preparación para la guerra (e incluso la guerra), y en esta forma orwelliana se estabiliza el significado de la palabra «paz»»». Vid. MARCUSE, H., «La tolerancia represiva», CAPALDI, N., Censura y libertad de expresión, Buenos Aires, Ediciones Libera, 1969, pp. 111-2.

${ }_{10}$ Refiriéndose a la entrada de los Estados Unidos en la última fase de la contienda bélica de la Primera Guerra mundial - entrada que invirtió la balanza en lo que ya daba la victoria a los alemanes-. Aseguraba que el odio de estos «norteamericanos» no se dirigía solamente contra la Alemania comercial o contra la Alemania militar. Se dirigía en especial contra la Alemania social porque, esa Alemania, se había mantenido, hasta entonces, fuera de los principios que gobernaban a los trusts mundiales». Vid. HITLER, A., «La 
De forma similar, Ford advertía, refiriéndose a los controvertidos Protocolos de los Sabios de Sión, que la propaganda hebrea tratada de alterar las opiniones colectivas. Apuntaba así, este magnate, que alterar no suponía algo significante ni detestable. Pero denunciaba que, al presentarse las verdades ficticias de forma apodíctica, rectilínea y cautivadora; durante un largo periodo de tiempo, se terminaba por dejar al descubierto su falsedad en forma de hechos y circunstancias destructoras y desmoralizadoras. ${ }^{11}$

Pero distanciándonos de las controversias en torno a estos dos últimos personajes; que ya forman parte de la historia, lo cierto es que la importancia de la función social y esencial de los medios de comunicación masivos, como public watchdog de la sociedad, frecuentemente queda subvertida por la difusión de mensajes que promueven intereses ajenos al bien común. Informaciones que, dependiendo del contexto en el que lleguen a ser vertidas, la importancia y seguimiento del medio de comunicación y la reiteración del mensaje; pueden llegar a infundir en la ciudadanía sentimientos e ideologías que distorsionan y atentan contra los intereses comunes e incluso contra la seguridad de las personas o las instituciones.

De esta forma, siguiendo a Butturini, el reparto de poderes mediáticos y el derecho a la manifestación y difusión de las ideas, a través del Derecho a la información, se termina convirtiendo en una libertad de manifestación del pensamiento ideológico del editor. Configurándose en una libertad de iniciativa económica privada $\mathrm{y}$, como tal, en un instrumento de presión políticoeconómico análogo al poder. ${ }^{12}$

\section{La prensa como vehículo transmisor de ideas, denuncia de atrocidades y} de controversias en la perspectiva de los tribunales

Advertido el controvertido rol de los servicios de la información, de informar y de incluso manipular a la sociedad; es preciso remachar que la

conspiración de la prensa internacional judía», CAPALDI, N., Censura y libertad de expresión, Buenos Aires, Ediciones Libera, 1969, pp. 133-4.

11 Vid. FORD, H., El Judio Internacional. Un problema del mundo, Resistencia, Ediciones Chaco, 1975, p. 165.

12 Por un lado, considera que el interés del público en conocer al propietario de la editorial y los fines de presión extra editoriales, políticos y económicos; determinan la información que condiciona la línea de pensamiento del diario. Y por otro, advierte que mediante la prohibición de un mercado oligopólico de empresas de servicios de información quedará garantizado el pluralismo. «L' indirizzo informativo viene quindi visto esclusivamente in chiave economica in un significado antioligopolistico». Vid. BUTTURINI. D., «L' informazione tra diritto individuale di libertà politico-economica e funzione di servizio pubblico», AA.VV., Studi in onore di Maurizio Pedrazza Gorlero, Edizione Scientifiche Italiane, Vol. II. La libertà di informazione e la democrazia constituzionale, 2014, p. 21. 
función mediática de public watchdog de la sociedad - identificada en Observer and Guardian vs. The United Kingdom y consolidada en Jersild vs. Dinamarca - es uno de los fundamentos esenciales de las sociedades democráticas que debe de estar protegido en la forma y contenido en el que las ideas y la información fueran expresadas. ${ }^{13}$

Al mismo tiempo, por ser las garantías de las que debe de disfrutar de una importancia especial, la prensa tiene el deber de impartir la información y las ideas mientras que el público tiene el derecho de recibirlas, dado que si fuese de otra forma, la prensa sería incapaz de desempeñar su papel de public watchdog,$^{14}$ mediante el cual los periodistas puedan llegar a exagerar, incomodar e incluso emitir declaraciones inmoderadas..$^{15}$

Al mismo tiempo, cómo hemos visto, al ser el posible impacto potencial, del medio en cuestión, un factor que se ha de tener en consideración; el TEDH ha venido manifestado que no se deben de sobrepasar el conjunto de límites admisibles por el CEDH en lo concerniente al abuse of rights del artículo $17 \mathrm{CEDH}$. Entre ellos, en interés de la seguridad nacional o el mantenimiento de la autoridad del poder judicial. ${ }^{16}$

De esta forma, sin precisar los supuestos concretos en los que específicamente se pudiera rebasar una frontera tan volátil advierte, la Corte europea, de la incumbencia que tiene la prensa en la difusión de mensajes de interés público y que, habida cuenta de que estos son especialmente perecederos, cualquier forma de intervención precisaría de un escrutinio más estricto. ${ }^{17}$ Precisándose in fine de un efecto mucho más inmediato y poderoso sobre los medios audiovisuales con respecto de los medios impresos. ${ }^{18}$

13 Vid. STEDH, de 7 de diciembre de 1976, Handyside vs. United Kingdom, párr. 49

14 Vid. STEDH, de 23 de septiembre de 1994, Jersild vs. Denmark, párr. 31.

15 Vid. STEDH, de 26 de abril de 1995, Prager and Oberschlick vs. Austria, 38; STEDH, de 28 de septiembre de 2000, Lopes Gomes da Silva vs. Portugal, párr. 34; STEDH, de 7 de noviembre de 2006, Mamère vs. France, párr. 25; STEDH, de 28 de junio de 2013, Novaya Gazeta and Borodyanskiy vs. Russia, párr. 29.

16 Vid. STEDH, de 26 de noviembre de 1991, Observer and Guardian vs. The United Kingdom, párr. 59.

${ }_{17}$ «On the other hand, the dangers inherent in prior restraints are such that they call for the most careful scrutiny on the part of the Court. This is especially so as far as the press is concerned, for news is a perishable commodity and to delay its publication, even for a short period, may well deprive it of all its value and interest». Vid. STEDH, de 26 de noviembre de 1991, Observer and Guardian vs. The United Kingdom, párr. 60

18 «In contemporary society radio and television are media of considerable power and influence. Their impact is more immediate than that of the print media, and the possibilities for the broadcaster to correct, qualify, interpret or comment on any statement made on radio or television are limited in comparison with those available to journalists in the press. Live statements could also involve a special risk of coded messages being conveyed, a risk which even conscientious journalists cannot control within the exercise of their 
Queda así expedita la facultad de que los sistemas democráticos puedan llegar a esgrimir una de sus herramientas más voraces; la aplicación mesurada de la censura desde los órganos de poder.

\subsection{La Corte suprema estadounidense y la teoría de la real malicia}

Al contrario del expuesto panorama europeo, dicha posibilidad quedó desterrada en la teoría desarrollada por los jueces Black y Douglas en el emblemático asunto New York Times Co. vs. United States. En él se advirtió que el papel de la prensa es el de servir a los gobernados y no a los gobernadores. ${ }^{19}$

La relevancia de este asunto, en el que la Corte Suprema estadounidense (USSC) formuló la teoría de la real malicie; constató, en este país, que el poder del gobierno para censurar la prensa fue abolido para que pudiera desnudar los secretos del gobierno e informar a las personas. Su formulación, no estuvo ausente de discrepancias, entre ellas, la oposición férrea del juez Burger quien recriminara la inexistencia de probabilidad de reprimir algo que no había sido emitido. ${ }^{20}$

Pero del mismo modo que el TEDH dejó expedita la vía a la censura temerosa de la verdad o de la subversión de la realidad del poder, la USSC admitió mucho tiempo atrás, en Near vs. Minnesota, que la libertad de expresión y de prensa pudiera ser restringida - en los supuestos de tiempo de guerra - contra publicaciones obscenas y en defensa de la seguridad colectiva ante actos de incitación a la violencia o intentos de derrocamiento del gobierno. ${ }^{21}$ Representando esta formulación un presupuesto que parece transgredir aquel ideal formulado por Madison, por el que the people, not the government, possess the absolute sovereignty. ${ }^{22}$

professional judgment». Vid. Decisión ComisiónEDH, de 16 de abril de 1991, Purcell and others vs. Ireland.

19 Vid. New York Times Co. vs. United States, 403 U.S., 717, 1971.

20 "Would it have been unreasonable, since the newspaper could anticipate the Government's objections to release of secret material, to give the Government an opportunity to review the entire collection and determine whether agreement could be reached on publication? Stolen or not, if security was not, in fact, jeopardized, much of the material could no doubt have been declassified, since it spans a period ending in 1968. With such an approach -- one that great newspapers have in the past practiced and stated editorially to be the duty of an honorable press -- the newspapers and Government might well have narrowed». Vid. New York Times Co. vs. United States, 403 U.S., 751, 1971

${ }^{21}$ Vid. Near vs. Minnesota, 283 U.S., 716, 1931.

22 «The legislature, no less than executive, is under limitations of power. Encroachments are regarded as possible from the one as well as from the other. Hence, in the United States, the great and essential rights of the people are secured against legislative as 


\subsection{La prensa en el Convenio Americano de Derechos Humanos - $\mathrm{CADH}-$}

Es en el continente americano donde ha quedado patentada la interdicción de la censura previa como condición sine qua non es posible ejercer el goce de los derechos reconocidos por la CADH. Esta convención, en esencia prohíbe, en su artículo 13, la censura previa en las comunicaciones. Sujetando su publicidad a ulteriores responsabilidades reguladas por una ley que podrá dejar únicamente en desafección de la misma a los espectáculos públicos, en orden de proteger a la infancia y la adolescencia.

Sobre esta materia tuvo la oportunidad de pronunciarse la ComisiónIDH en el asunto Martorell, un proceso proveniente de la Corte de Apelaciones de Santiago de Chile que avalaría la prohibición de la distribución del libro Impunidad diplomática en aras de proteger el honor y la dignidad de las personas.

Pero la respuesta de la ComisiónIDH fue taxativa,

La interdicción de la censura previa, con la excepción que prevé el párrafo 4 del artículo 13, es absoluta. Esta prohibición existe únicamente en la Convención Americana. La Convención Europea y el Pacto sobre Derechos Civiles y Políticos no contienen disposiciones similares. Constituye una indicación de la importancia asignada por quienes redactaron la Convención a la necesidad de expresar y recibir cualquier tipo de información, pensamientos, opiniones e ideas, el hecho de que no se prevea ninguna otra excepción a esta norma. ${ }^{23}$

De lo contrario, implicaría «dejar al libre arbitrio de los órganos del Estado la facultad de limitar, mediante censura previa, el derecho a la libertad de expresión». ${ }^{24}$

\subsection{El secuestro de las comunicaciones y su imbricación constitucional}

Posiblemente el problema más relevante en el supuesto de la incautación de una información que aún no fuere emitida es el desbordamiento constitucional

well as executive ambition. They are secured, not by laws paramount to prerogative, but it by constitutions paramount to laws. This security of the freedom of the press requires that it should be exempt, not only from previous restraint of the executive, as in Great Britain, but from legislative restraint also; and this exemption, to be effectual, must be an exemption, not only from the previous inspections of licensers, but from the subsequent penalty of laws. The state of the press, therefore, under the common law, cannot in this point of view, be the standard of its freedom in the United States». Vid. MADISON, J., The debates in the several state conventions, on the adoption of the Federal Constitution, Washington, Jonathan Elliot, Vol. IV, 1836, pp. 569-570.

${ }^{23}$ Vid. Martorell vs. Chile, de 3 de mayo de 1996, párr. 56. Informe núm. 11/96.

${ }^{24}$ Ibídem, párr. 73. 
que ello conlleva. Efectivamente, si se pudiera desvirtuarse la teoría del juez Burger y, preverse, ex ante, que los contenidos de un mensaje producirán un daño irreparable; se presenta controvertido sostener que la prevención, por si sola, superará el debido escrutinio de prevención del abuso del derecho.

Siguiendo a De Luca, no es posible aceptar la censura basada en el principio de prevención de daños dado que a través de la coacción de la tipificación ulterior a la divulgación de la información, la ley penal «cumplirá su papel disuasorio como lo hace en cualquier otro delito o acción antijurídica, pero deviene inconstitucional impedir una publicación o comunicación so pretexto de prevenir la consumación de los daños que tal expresión conlleva». ${ }^{25}$ En sus razonamientos, considera que, al quedar restringida de forma constitucional la persecución del delito de expresión a través de la prensa en grado de tentativa, quedaría anulada la posibilidad de una agresión ilegítima entre autoridades y particulares que pudiera ser impedida o repelida por una acción defensiva.

Pero este mecanismo serviría de poco si se mantiene un sistema de responsabilidad ulterior automática que llame a la censura indirecta o chilling effect: «Un sistema tal generaría la autocensura ante la certeza de la segura sanción posterior con el efecto de enfriamiento del flujo de ideas». ${ }^{26}$

En esta misma línea se ha situado la Relatora Especial sobre la situación de los defensores de los derechos humanos de la ONU. Advierte del grave deterioro de la libertad de opinión y expresión a través de la legislación relativa a la seguridad nacional y la tipificación penal lo cual conduce al autosilenciamiento mediático - chilling effect-

Dada la importancia creciente de los medios de comunicación social y otros medios de comunicación en línea, los Estados han tratado de reglamentar estos, a menudo con consecuencias perjudiciales para las actividades de los defensores. Las disposiciones en que se penaliza la publicación de artículos o fotografias que pudieran atentar contra la seguridad nacional, el orden público, la salud pública o el interés público, incitar a la violencia, constituir sedición o tener consecuencias negativas para el clima financiero del país son excesivamente genéricas y restrictivas. No es solo que esas disposiciones limiten la capacidad de los defensores de los derechos humanos de expresar su opinión acerca de cuestiones de derechos humanos, sino que también les dificultan el saber lo que es admisible con arreglo a la ley y, por ende, los abocan a la autocensura. ${ }^{27}$

${ }^{25}$ Vid. DE LUCA, A. J., Libertad de prensa y delitos contra el honor: delitos contra el honor cometidos a través de la prensa..., p. 348.

${ }^{26}$ Vid. DE LUCA, A. J., Libertad de prensa y delitos contra el honor: delitos contra el honor cometidos a través de la prensa..., p. 349.

27 Vid. Asamblea General de las Naciones Unidas, Informe de la Relatoría Especial, «Situación de los defensores de los derechos humanos», de 8 de agosto de 2012 , 
Este aparente respeto por el flujo de ideas no parece tener un arraigue tan profundo en Europa y, como bien expresa la ComisiónIDH, a priori, parece únicamente darse la letra en la CADH. De esta forma, las susceptibilidades que puedan surgir respecto al posible enmascarado silenciamiento contra los críticos del Estado, a través de la previa reglamentación a la que se ven sometidos los medios para poder emitir sus mensajes, ${ }^{28}$ son desbordadas a través de la fórmula democrática con la que el Estado actúa como un enemigo de la democracia restringiendo las libertades del disidente basándose en cuestiones de seguridad nacional y terrorismo. ${ }^{29}$ Todo ello sin obviar la fórmula de emplear - tanto por el gobierno cómo por la oposición - a los medios de comunicación para desinformar a la ciudadanía y utilizarlos como canal de perpetración de sus objetivos ilegítimos.

Esta es una de las lecciones que debiéramos haber aprendido de los diferentes conflictos bélicos; como el de las guerras de los Balcanes, donde los medios de comunicación jugaron un papel clave para legitimar la continuidad de un largo y cruento conflicto. ${ }^{30}$ En aquel, cómo en todos, la instrumentalización de la propaganda fue utilizada por todos los bandos beligerantes. Y, cómo apunta Serrano, sin su empleo parece que hubiera sido muy difícil que hubiese estallado la guerra. ${ }^{31}$ De hecho, a pesar de que fuera más más complicado encontrar un medio de comunicación independiente en Croacia que en Serbia, ${ }^{32}$ la criminalización mediante el empleo de la propaganda fue

A/67/292, párr. 24.

28 Vid. FISS, O., Libertad de Expresión y Estructura Social, Malem Seña, J. (Trad.), México D.F., Distribuciones Fontamara, S.A., 1997, p. 200.

${ }^{29}$ Ibídem, p. 180. Del mismo modo: Vid. La emergencia del miedo, ZAFFARONI, E.R., FERRAJOLI, L., TORRES, S. G., BASILICO, R. A., La emergencia del miedo, Buenos Aires, Ediar, 2012

${ }^{30}$ Según consta en los informes de la OSCE, la campaña serbia de terror comenzó en el momento en el que a OTAN inició sus bombardeos el 24 de marzo de 1999 y no de forma anterior. Un periodo de odio cultivado desde la época nazi, en la que albaneses y serbios acumularon gran cantidad de odio. Y donde el odio del ocupante no puede ser comparable con el del ocupado. Vid. OSCE, HAXIU, D., «Kosovo - Where the Dead Speak», Freedom and Responsibility, Yearbook 1999/2000, Vienna, Office of the Representative on Freedom of the Media, 2000, p. 40.; Advierte Jimenéz Moliner que, desde entonces, los medios de comunicación contribuyeron a infundir la convicción de que los hermanos serbios se encontraban amenazados por otras etnias mayoritarias en las provincias vecinas y que la acción bélica preventiva era el único modo de cumplir con la obligación de defenderlos y rescatarlos. Vid. JIMÉNEZ MOLINER, A., «Medios de comunicación y hate speech en las sociedades post-totalitarias: el paradigma de Kosovo», Cuadernos de la Cátedra Fadrique Furió Ceriol, núms. 50/51, 2005, p. 135.

31 Vid. SERRANO, P., Medios violentos. Palabras e imágenes para el odio y la guerra, El Viejo Topo, 2008, p. 42.

32 Ibídem, p. 45. 
uno de los factores esgrimidos por Croacia contra Serbia en su acusación mutua por crímenes de genocidio ante la Corte penal internacional. ${ }^{33}$

En la misma línea, con unos efectos aún más devastadores, implacables fueron las circunstancias que convirtieron a Radio Televisión Libre de las Mil Colinas (RTLMC) en la arteria decisiva para el llamamiento a la masacre en Ruanda. Un lugar en el que buena parte de la población no era capaz de leer ni escribir, y que posibilitó que la radio se convirtiera, de forma eficaz, en el vehículo de control y manipulación de las masas; favoreciendo el desencadenamiento de las trágicas consecuencias finales que todos conocemos. ${ }^{34}$

Tanto en Ruggiu, ${ }^{35}$ como en Nahimana et al.,${ }^{36}$ la CPI para Ruanda consideró que el papel de los medios de comunicación fue utilizado de

33 «Croatia argues that the scale and consistent nature of the crimes committed by the JNA and Serb forces evince a clear intention to bring about the physical destruction of the Croats. It contends that these crimes constitute a pattern of conduct from which the only reasonable inference to be drawn is that the Serb leaders were motivated by genocidal intent. Croatia thus sets out a series of 17 factors which it believes, individually or taken together, could lead the Court to conclude that there was a systematic policy of targeting Croats with a view to their elimination from the regions concerned: (1) the political doctrine of Serbian expansionism which created the climate for genocidal policies aimed at destroying the Croat population living in areas earmarked to become part of «Greater Serbia»; (2) the statements of public officials, including demonization of Croats and propaganda on the part of State-controlled media...». Vid. SICT, de 3 de febrero de 2015, Croatia vs. Serbia, párr. 408, p. 112.

${ }^{34}$ From the opening days of the war, the government understood the importance of using media to rally Rwandans around the regime. Believing that the government-controlled media were not up to the task of carrying forward a vigorous propaganda campaign. Vid. DES FORGES, A., "Call to Genocide: Radio in Rwanda, 1994», THOMPSON, A. (Edit.), The Media and the Rwanda Genocide, London, Pluto Press, 2007, p. 42. Para un estudio más amplio, entre otros: Vid. GORDON, G. S., «Hate Speech and Persecution: A Contextual Approach», Vanderbilt Journal of Transnational Law, Vol. 46, núm. 2, 2013.

35 «Those acts were direct and public radio broadcasts all aimed at singling out and attacking the Tutsi ethnic group and Belgians on discriminatory grounds, by depriving them of the fundamental rights to life, liberty and basic humanity enjoyed by members of wider society. The deprivation of these rights can be said to have as its aim the death and removal of those persons from the society in which they live alongside the perpetrators, or eventually even from humanity itself». Vid. SICTR, de 1 de junio de 2000, The Prosecutor vs. Georges Ruggiu. Case núm. ICTR-97-32-I, párr. 22.

${ }^{36}$ «In Ruggiu, the Tribunal so held, finding that the radio broadcasts of RTLM, in singling out and attacking the Tutsi ethnic minority, constituted a deprivation of «the fundamental rights to life, liberty and basic humanity enjoyed by members of the wider society». Hate speech is a discriminatory form of aggression that destroys the dignity of those in the group under attack. It creates a lesser status not only in the eyes of the group members themselves but also in the eyes of others who perceive 
forma sistemática para la movilización de la población a gran escala. Deduciendo de su examen la necesidad de considerar algo más que el contenido de los mensajes. Principalmente por su aplicación y propagación mediática. ${ }^{37}$

Por todo ello, consideramos que únicamente aquellas expresiones incendiarias, que sean vertidas en un medio de difusión masiva y que supongan un clear and imminent danger para la sociedad, deben de ser susceptibles de intervención penal $\mathrm{y}$, de proseguir, de la consecuente incautación judicial especializada de las comunicaciones.

\section{EL TRIBUNAL EUROPEO DE DERECHOS HUMANOS Y LA RADICALIZACIÓN MEDIÁTICA}

El posicionamiento del TEDH en lo concerniente a la difusión mediática de mensajes caracterizados por una aparente radicalización, no resulta clara y menos homogénea. Para identificarlo nos vamos a servir del estudio comparado de dos asuntos ya juzgados y referentes al mismo país.

El primero relacionado con la difusión de información referente al Partido los Trabajadores del Kurdistán «PKK» (o también: «KADEK», «KONGRAGEL») antes de ser incluido, en el año 2002, en la lista de organizaciones terroristas de la Unión Europea surgida de la aplicación de los artículos 2, 3 y 4 de la Posición Común 2001/931/PESC sobre la aplicación de medidas específicas de lucha contra el terrorismo. ${ }^{38}$

Por su parte, el segundo de los casos refiere a la perseverante anatemización que el Estado turco ha venido realizando sobre aquellos que han tratado de señalar al imperio Otomano como responsable del Genocidio armenio.

\section{Sürek vs. Turquía, de 8 de julio de 1999}

En agosto de 1992, fueron divulgadas dos cartas en el diario turco Haberde Yorumda Gerçek (La Verdad de Noticias y Comentarios) propiedad de Kamil Tekin Sürek. Las mismas, fueron publicadas en la sección de cartas de los lectores con los títulos Silahlar Özgürlüğ̈̈ Engelleyemez «Las armas

and treat them as less than human. The denigration of persons on the basis of their ethnic identity or other group membership in and of itself, as well as in its other consequences, can be an irreversible harm». Vid. SICTR, de 28 de noviembre de 2007, Ferdinand Nahimana et. al. vs. The Prosecutor. Case núm. ICTR-99-52-A, párr. 86.

37 Ibídem, párr. 693.

38 Vid. DOCE, L295 de 30 de octubre de 2002, p. 3. 
no pueden vencer la libertad ${ }^{39}$ y Suc Bizim «Es nuestra culpa»; ${ }^{40}$ y fueron redactadas en un contexto político que, perdura hoy día de forma virulenta, que se escapa a las pretensiones de este estudio, y del que prácticamente existe una única fuente de información a la que el TEDH, por cierto, ni siquiera refiere.

En la primera de las cartas se denunciaba la masacre en la ciudad de Şırnak ejecutada, días antes, por el ejército turco como respuesta a la escalada bélica del PKK. ${ }^{41}$

Por su parte, la segunda de las cartas, refería las masacres perpetradas por Turquía contra los kurdos. Y, en un mensaje que consideramos importante para este estudio, se preguntaba: «Pero, ¿qué pasa con la culpabilidad de los charlatanes, los que están frustrando la lucha por la democracia y la libertad?... Sí, ¿qué pasa con su culpa?... Ellos tienen su parte en los asesinatos....» ${ }^{42}$

Como titular de la revisión y editor de la revista, Sürek fue procesado por el İstanbul Devlet Güvenlik Mahkemesi - Tribunal de Seguridad Nacional de Estambul - por difundir en su revista propaganda contra la indivisibilidad del Estado y provocar la enemistad y el odio entre las personas. Todo ello en base al artículo 312 del Código penal turco y al artículo 8 de la Ley de Prevención del Terrorismo de $1991 .{ }^{43}$

${ }^{39}$ Las dos cartas que, fueron redactadas por lectores independientes, versaban sobre el inacabable conflicto en el Kurdistán y su interminable sangría. Por aquel entonces principalmente a manos iraquíes y turcas. En la primera de las cartas se denuncia la masacre perpetrada por «el ejército turco fascista [que] continúa llevando a cabo atentados [...] La masacre llevada a cabo en Halepçe en el sur del Kurdistán, por la administración reaccionaria BAAS, está teniendo lugar en el norte del Kurdistán. [...] Sirnak es la forma más efectiva de la campaña que se libra en toda Turquía para erradicar a los kurdos. [...] Cada ataque lanzado por la República de Turquía para acabar con los kurdos intensifica la lucha por la libertad. [...] El pueblo kurdo, que está siendo despojado de sus hogares y de su patria, no tienen nada que perder. Pero tienen mucho que ganar». Vid. STEDH, de 8 de julio de 1999, Sürek vs. Turkey, párr. 11.

${ }^{40}$ Refería al Estado turco como panda de asesinos que por motivos de seguridad de la República de Turquía continúan asesinando. Advertía que «a medida que la gente despierta, aprende gradualmente a defender sus derechos y la idea de que «si nos van a dar, entonces vamos a tomar por la fuerza», germina poco a poco en la mente de la gente». Ibídem, párr. 11.

${ }^{41}$ «One of the better know of such attacks took place in the town of Şırnak on 18 August 1992 and lasted for two days with the city cut off from the outside world until 21 August. As a response to the PKK's attack targeting state buildings, the security forces opened random fire at the town's houses and businesses». Vid. GUNES, C., The Kurdish National Movement in Turkey. From protest to resistance, Oxon, Routledge, 2012, p.131.

${ }^{42}$ En un tono más irónico se dirigían a los servidores del imperialismo -refiriéndose a los nacionalistas turcos- y también a todos aquellos que generan una conciencia reaccionaria en contra del Kurdistán. Vid. STEDH, de 8 de julio de 1999, Sürek vs. Turkey, párr. 11.

43 « (1) Written and oral propaganda and assemblies, meetings and demonstrations aimed at damaging the indivisible unity of the Turkish Republic with its territory and 
En su defensa Sürek negó los cargos que le imputaban por provenir de opiniones vertidas en el ejercicio de la libertad de expresión de los lectores de la revista, y no de las suyas propias.

Condenado en abril de 1993, al pago de 200 millones de liras turcas (unos 62.000 euros), el Tribunal de Seguridad Nacional de Estambul subrayó que las publicaciones referían al estado independiente del Kurdistán y describió al PKK como un movimiento de liberación nacional que participa en una guerra por la independencia nacional y que dirige su propaganda a la destrucción de la integridad territorial del Estado turco. ${ }^{44}$

A pesar de la abundante jurisprudencia en contra de su procesamiento. En las que los tribunales de Seguridad Nacional turcos, que trataban el problema Kurdo, llegaron a la conclusión de que no había habido propaganda. ${ }^{45}$ Las diversas apelaciones en la Corte de Casación fueron desestimadas.

Agotada la vía nacional Sürek apeló ante la Comisión Europea de Derechos Humanos -ComisiónEDH- por considerar vulnerado su Derecho a un tribunal imparcial el el Derecho a la libertad de expresión (artículos 6 y 10 del CEDH). Circunstancias por las que la ComisiónEDH consideró (19/13) que no hubo violación del artículo $10 \mathrm{CEDH}$, pero sí del artículo $6 \mathrm{CEDH}^{46}$

\section{1. ¿Existe la posibilidad de llegar a estigmatizar y provocar a una de las partes beligerantes de un conflicto desde la sección de cartas de un diario? El TEDH adalid del Estado}

Llegado el asunto ante el TEDH, este limitó el análisis del fondo a la posible vulneración de los artículos 6 y 10 del CEDH. Interesando a este estudio el análisis del artículo 10 frente a lo que el TEDH no cuestionaba que resultase vulnerada la libertad de expresión de Sürek.

Con el fin de determinar si la injerencia era justificada, anotó que la ComisiónEDH apreció que la redacción del artículo 8 de la Ley de prevención del terrorismo turca contenía una redacción vaga que podía poner en

nation are forbidden [...] (2) If the offence of propaganda as mentioned in the foregoing paragraph is committed by a periodical as defined in Article 3 of the Press Law No. 5680, its publishers shall be punished additionally [...] Vid. Propaganda against the indivisible unity of the State, Law no. 3713 of 12 April 1991, Artículo 8.

${ }_{44}$ Vid. STEDH, de 8 de julio de 1999, Sürek vs. Turkey, párr. 15.

${ }^{45}$ De la documentación aportada por el gobierno se podía comprobar que en la mayoría de los casos los hechos habían sido cometidos por medio de publicaciones similares que, o habían prescrito, o no fueron distribuidas, o no hubo pruebas suficientes, o no existía intención... Además, fueron aportadas unas 85 sentencias exculpatorias, del periodo comprendido entre 1991-1998. Ibídem, párrs. 29-31.

46 Vid. Decisión ComisiónEDH, de 2 de diciembre de 1997, Kamil Tekin Sürek vs. Turkey. 
duda el cumplimiento de los requisitos de claridad y previsibilidad inherentes al test «prescrito por la ley». ${ }^{47}$

En lo que respecta al fin legítimo perseguido. La postura del TEDH fue incapaz de situarse en medio de la línea de fuego que separa las dos partes beligerantes de un conflicto que arrastra décadas. Refiriéndose al asunto Zana ${ }^{48}$ advirtió, eso sí, la delicada situación que se vive en el sudeste de Turquía y la necesidad de que las autoridades estén en alerta. De ello apreció que «las medidas tomadas contra el solicitante se puede decir que [fueron] en cumplimiento de algunos de los objetivos mencionados por el Gobierno, a saber, la protección de la seguridad nacional e integridad territorial y la prevención del desorden y el crimen». ${ }^{49}$

Cumplidos así los dos estándares iniciales faltaría por determinar si las medidas adoptadas fueron necesarias en una sociedad democrática.

En su defensa Sürek recordó que su opinión no tenía ningún vínculo alguno con organizaciones terroristas, ni era el responsable de editar los contenidos de la sección de cartas de la editorial. Sus argumentaciones fueron rechazadas por la ComisiónEDH qué consideró las cartas impugnadas como estimulantes para la comisión de nuevos actos de violencia. ${ }^{50}$

De esta forma, buscando el equilibrio entre la necesidad y la proporcionalidad del objetivo legítimo perseguido por las acciones. Y si los motivos invocados fueron pertinentes y suficientes. El TEDH consideró que las cartas condenaron «vehementemente las acciones militares de las autoridades en el sureste de Turquía y los acusaron de la brutal represión del pueblo kurdo en su lucha por la independencia y la libertad». ${ }^{51}$

${ }^{47}$ El TEDH, pese a considerar la vaguedad de la redacción del artículo 8 de la Ley de prevención del terrorismo de 1991, admitió que, dado que la condena se basó en ese artículo 8; la interferencia resultante con el derecho a la libertad de expresión pudo considerarse prescrita por la ley. Especialmente porque el demandante no lo rechazó. Vid. STEDH, de 8 de julio de 1999, Sürek vs. Turkey, párrs. 47-8.

48 Vid. STEDH, de 25 de noviembre de 1997, Zana vs. Turkey, párrs. 10-11.

49 Ignorando completamente la realidad de una situación de fuego cruzado, y la masacre perpetrada por las fuerza turcas en la ciudad de Şırnak, el TEDH se sitúa de forma completamente parcial en el bando del Estado turco, afirmando que es especialmente cierto que la situación en el sudeste de Turquía, «en el momento de las circunstancias del caso, el movimiento separatista recurrió a métodos que se basan en el uso de la violencia». Vid. STEDH, de 8 de julio de 1999, Sürek vs. Turkey, párr. 52.

${ }^{50}$ Vid. Decisión ComisiónEDH, de 2 de diciembre de 1997, Kamil Tekin Sürek vs. Turkey, párr. 67.

${ }^{51}$ Considera que en la segunda carta titulada «Las armas no pueden ganar contra la libertad» el autor hace referencia a que las dos masacres «se cometieron intencionalmente por las autoridades como parte de una campaña estratégica para erradicar los kurdos». Pero el TEDH omite nuevamente el reconocimiento de un conflicto silenciado por Tur- 
Omitiendo el deber de observar de forma global la interferencia en su conjunto - recordemos que días antes a la publicación se produjo una carnicería en la ciudad de Şırnak - incluyendo el contenido de las declaraciones impugnadas y el contexto en el que fueron realizadas. $\mathrm{Y}$, pese a reconocer taxativamente la existencia de un conflicto, ${ }^{52}$ declinó el TEDH la balanza en beneficio del Estado sosteniendo que hubo

una clara intención de estigmatizar a la otra parte en el conflicto mediante el uso de calificativos como "el ejército fascista turco», «el TC [se refiere aqui a la República de Turquía] banda de asesinos» y «los asesinos a sueldo del imperialismo» junto a referencias a «masacres», brutalidades» $y$ «palizas». En opinión de la Corte las cartas impugnadas, constituyen una apelación a la venganza sangrienta, dado que despierta instintos básicos y endurece prejuicios anclados que se han manifestado en actos de violencia profunda. ${ }^{53}$

Desconociendo el fondo del asunto, tales contenidos, sin duda alarmantes, serían del todo preocupantes si fueran difundidos en un diario de máxima audiencia. Sin embargo, es llamativo que la Corte europea, conocedora de la dramática situación reinante en el sudeste de Turquía - que desde 1985 reconoce se han perdido numerosas vidas humanas - rehúsa reconocer el genocidio que, de forma continuada, se está perpetrando contra el pueblo kurdo. Al contrario de lo anterior afirmó que, en aquel contexto, «el contenido de las letras es capaz de incitar a una mayor violencia en la región instigando un odio profundo e irracional contra los representados como responsables de las supuestas atrocidades. De hecho el mensaje que se comunica al lector es que el recurso a la violencia es una medida necesaria y justificada en el conferimiento de la autodefensa». ${ }^{54}$

De esta forma, un tanto distanciada, consideró que la sanción impuesta respondía a una necesidad social imperiosa y que las razones aducidas fueron pertinentes y suficientes, razón por la que la, Gran Sala del TEDH, compuesta por diecisiete jueces y presidida por el juez suizo Luzius Wildhaber, consideró (11/6) que no existió violación del artículo 10 del CEDH; y que sí se produjo, en cambio, (16/1) una violación del artículo 6 por la presencia de un juez militar.

\subsection{Pero, ¿podrían realmente incitar a la violencia las notas de la sección de cartas de los lectores? Real or genuine risk of the speech test}

Interesa en este punto indicar que en ningún momento se trató de buscar la responsabilidad de los autores materiales de las publicaciones. Además, en

quía en el que todo parecía indicar que las autoridades turcas participaron de forma activa en la masacre. Vid. STEDH, de 8 de julio de 1999, Sürek vs. Turkey, párr. 60.

52 Ibídem, párr. 58 (iii).

${ }^{53}$ Ibídem, párr. 62.

${ }^{54}$ Ibídem, párr. 62. 
ninguna parte del largo procedimiento judicial fue baremado el grado de relevancia que pudiera representar la sección de cartas de los lectores, o fuera valorado el que una nota de prensa marginada en un periódico pudiera llegar a cautivar a su tímida audiencia. Todo ello sin considerar la propia causa nuclear del conflicto del Kurdistán.

Lo más llamativo de lo anterior es que enajenando estos apuntes el TEDH eludió su propia jurisprudencia al no evaluar la relevancia del medio y el impacto potencial que pudiera causar en su audiencia:

it is recalled that the potential impact of the medium of expression concerned is an important factor in the consideration of the proportionality of an interference $e^{55}$

Tampoco advirtió la Corte que los medios audiovisuales disponen de un efecto mucho más inmediato y enérgico que los medios escritos

In contemporary society radio and television are media of considerable power and influence. Their impact is more immediate than that of the print media, and the possibilities for the broadcaster to correct, qualify, interpret or comment on any statement made on radio or television are limited in comparison with those available to journalists in the press ${ }^{56}$

A tenor de lo expuesto, los posibles efectos enérgicos del mensaje quedarían volatilizados en una desterrada difusión, de un diario de audiencia limitada, en la sección de cartas de los lectores. Resultando, en suma, tan limitada la posibilidad de cautivar a una audiencia tan tímida que en su propia curiosidad perdería incluso el poder de convicción. Todo ello sin contar, como apunta McGonagle, que cualquier persona interesada en leer el periódico debiera previamente acudir a un quiosco para comprarlo con el fin de confrontar sus contenidos. ${ }^{57}$

Para poder profundizar en estas últimas reflexiones interesa prestar especial atención a algunos de los votos disidentes expresados por los jueces del TEDH en Sürek. Especialmente, por lo particular del caso - presunta incitación al odio en un contexto bélico- y por la ausencia de sólidas argumentaciones en la opinión mayoritaria de la Corte.

Tal es la importancia del asunto que la juez sueca Elisabeth Palm consideró, en voto disidente, que se había prestado demasiada importancia al

55 Vid. STEDH, de 3 de diciembre de 2003, Murphy vs. Ireland, párr. 69.

56 Entre otras: Vid. Decisión ComisiónEDH, de 16 de abril de 1991, Purcell and others vs. Ireland; STEDH, de 23 de septiembre de 1994, Jersild vs. Denmark, párr. 31; STEDH, de 3 de diciembre de 2003, Murphy vs. Ireland, párr. 69; STEDH, de 30 de marzo de 2004, Radio France and others vs. France, párr. 39.

57 Vid. McGONAGLE, T., Minority Rights, freedom of Expression and of the Media: Dynamics and Dilemmas, op. cit., pp. 341-2. 
lenguaje duro y mordaz de las cartas en detrimento de una insuficiente atención al contexto general y su probable impacto. En su tesis aducía que resultaba preciso centrarse menos en la vehemencia y el tono escandaloso de las palabras y más en los diferentes elementos del entorno contextual en el que se pronunció el discurso. "Was the language intended to inflame or incite to violence? Was there a real and genuine risk that it might actually do so?». ${ }^{58}$

Para dar una respuesta adecuada, indica, se requiere de una evaluación de las numerosas capas que componen el contexto general y considera importante advertir que Sürek fue castigado por cuatro diferentes parámetros:

1) Por un delito de difusión de propaganda separatista y no por incitación al odio prevista en el artículo 312 del Código penal turco.

2) Porqué ser el principal accionista de la revisión y no por ser el autor de las cartas impugnadas.

3) Ni Sürek, ni los autores de las cartas, eran figuras prominentes en la vida turca con capacidad de ejercer una influencia en la opinión pública.

4) Que la revisión se publicó en Estambul lejos de la zona de conflicto en el sureste de Turquía.

5) Que la sección de cartas de los lectores no ocupaba una posición central. Y, por su propia naturaleza, era de influencia limitada; siendo preciso conceder al público mayor flexibilidad para expresar su punto de vista de forma más vehemente que la que se le exigiría a un periodista profesional.

De esta forma, en atención a todos esos factores, y estableciendo una especie de similitud con aquel test de Holmes, apuntó la juez Palm

«that there was no real or genuine risk of the speech at issue inciting to hatred or to violence». ${ }^{59}$

b) Giovanni Bonilla y la reformulación del clear and present danger test

Crítico con la forma de proceder de los tribunales en los últimos casos en los que la libertad de expresión había resultado violada por las autoridades

${ }^{58}$ Refiriendo el asunto Zana vs. Turkey recordó que el TEDH examinó el contexto en que se hizo la declaración, señalando: 1) Que la entrevista coincidió con ataques y asesinos llevados a cabo por el PKK contra civiles en el sudeste de Turquía, donde la tensión extrema reinaba en la época de los hechos. 2) Que el demandante era el alcalde de Diyarbakir -la ciudad más importante en el sureste de Turquía-. 3) Que la entrevista había sido difundida en un diario nacional importante. Ibídem, Voto disidente de la juez Palm, p. 34.

${ }^{59}$ Ibídem, Voto disidente de la juez Palm, p. 37. 
turcas, el juez maltés Giovanni Bonilla, consideró que únicamente es justificable restringir la libertad de expresión cuando las publicaciones apoyen o instiguen al empleo de la violencia.

Evocando el test de Holmes, en Abrahams vs. United States, consideró que únicamente sería justificable el castigo de este tipo de mensajes si la incitación pudiese crear un clear and present danger.$^{60} \mathrm{Y}$ trasladándolo al caso no le resultaba evidente que los mensajes por los que fue acusado Sürek tuviesen el potencial de amenazar inminentemente; con efectos terribles en el orden nacional, ni que su supresión inmediata fuese indispensable para la salvación de Turquía.

[N]o danger flowing from speech can be deemed clear and present, unless the incidence of the evil apprehended is so imminent that it may befall before there is opportunity for full discussion. If there be time to expose, through discussion, the falsehood and the fallacies, to avert the evil by the process of education, the remedy to be applied is more speech, not enforced silence ${ }^{6 l}$

c) Imposibilidad de juzgar el contenido de un mensaje sin evaluar su contexto

Por su parte, los jueces Françoise Tulkens (Bélgica), Josep Casadevall (Andorra) y Hanna Sophie Greve (Noruega), consideraron que la libertad de expresión podría ser únicamente limitada cuando tiende directamente provocara la comisión de un delito grave.

Denunciaron a su vez estos jueces que en Sürek la Gran Sala del TEDH se distancia de otros casos similares como Zana, donde la tensión extrema existía y los mensajes provenían de una figura política con capacidad de agravar una situación. Ya de por si explosiva en la región. ${ }^{62}$

Como nota destacable, y en concordancia con los anteriores, el juez luxemburgués Marc Fischbach advirtió de la situación existente del sudeste de Turquía desde 1985. Y apuntó que lo que divulgaron los lectores describía, en términos violentos y chocantes, lo que sucede en la región. ${ }^{63}$

Referente a esta última valoración, autores como Rowbottom han resaltado, de forma equidistante, la necesidad de que todos los medios de comunicación masiva y especialmente los servicios de información pública por su poderoso impacto y estatus de fuente de información creíble, deban de tener

${ }^{60}$ Ibídem, Voto disidente del juez Bonilla, p. 36.

${ }^{61}$ Atendiendo al célebre voto de Brandeis en Whitney vs. California. Ibídem, Voto disidente del juez Bonilla, p. 37.

${ }^{62}$ Ibídem, Votos disidentes de los jueces Tulkens, Casadevall y Greve, p. 38.

${ }^{63}$ Ibídem, Voto disidente del juez Fischbach, p. 40. 
una responsabilidad especial con el fin de evitar divisiones sociales exacerbadas. $^{64}$

La referida responsabilidad mediática debiera de incrementarse, aún más, cuando el contexto refiere un conflicto bélico frente al que se debe de tomar una especial caución. En tales circunstancias, advierten Ovey y White, los periodistas tienen especiales deberes y responsabilidades al poder convertirse en "'a special vehicle for the dissemination of hate speech and violence' $\gg{ }^{65}$

Esta caución, sin embargo, pudiera a su vez disuadir la difusión de informaciones que comprometieran, como en aquel caso, la imagen de un Estado. Lo cual daría lugar al ensombreciendo de la otra cara de la realidad de un conflicto en el que ambas partes pueden ser igualmente responsables. ${ }^{66}$

Interesa aquí recordar que, siendo el asunto Sürek anterior a la inclusión del PKK en el referido listado de organizaciones terroristas de la Unión Europea,${ }^{67}$ años después de su inclusión, la propia Corte de Estrasburgo terminó reconociendo que la cuestión en torno al PKK y su inclusión en el listado de organizaciones terroristas no estaba motivada.$^{68}$

${ }^{64}$ Vid. ROWBOTTOM, J., «Extreme Speech and Democratic Functions of the Mass Media», HARE, I., WEINSTEIN (Edits.), J., Extreme speech and democracy, Oxford University Press, 2009, p. 625.

${ }^{65}$ Vid. OVEY. C., y WHITE, R. C. A, Jacobs and White: The European Convention on Human Rights, Fourth Edition, Oxford, Oxford University Press Inc., 2006, p. 321.

${ }^{66}$ Baste recordar que este es uno de los conflictos que han perseverado latentes en todo el siglo XX y no se presentan solubles en el actual siglo XXI. Por poner un ejemplo, ya analizado por el TEDH, el 26 de marzo de 1994 las fuerzas armadas turcas bombardearon los pueblos de Kuşkonar y Koçağili causando multitud de muertes (en su mayoría mujeres, ancianos y niños), presumiblemente porque colaboraban con el PKK. Turquía no reparó en acusar del ataque al PKK. Pero, según se constató en las investigaciones en sede de Estrasburgo, las investigaciones realizadas por las autoridades turcas no fueron imparciales ni independientes, enfatizando, en lo referente a la responsabilidad de los hechos que «the Court concluded that the Turkish government had conducted an aerial attack killing 33 of the applicants' relatives and injuring three of the applicants themselves, in violation of Article 2». Vid. STEDH, de 12 de noviembre de 2013, Benzer and others $v$. Turkey.

${ }^{67}$ Incluído actualmente a pesar de la meritoria controversia internacional surgida en torno a ello y a las actividades bélicas del Estado turco. Vid. DOUE, L209, de 9 de agosto de 2019, Decisión (PESC) 2019/1341 del Consejo de 8 de agosto de 2019, por la que se actualiza la lista de personas, grupos y entidades a los que se aplican los artículos 2, 3 y 4 de la Posición Común 2001/931/PESC sobre la aplicación de medidas específicas de lucha contra el terrorismo y se deroga la Decisión (PESC) 2019/25, Anexo.

${ }^{68}$ El Reglamento de ejecución del Consejo de la Unión Europea núm. 125/2004, por el que se incluía al PKK en la lista terrorista, se apoyaba principalmente en una Decisión del Home Secretary (Ministro del Interior, Reino Unido), de 29 de marzo de 2001, por la que se prohibía el PKK en virtud de la UK Terrorism Act 2000 y en una decisión del Go- 
Es por ello, por lo que la función de la prensa es esencial para dar a conocer la versión más amplia de cada conflicto, por lo que debe de brindar la imagen más fiel de todas y cada una de las opiniones circundantes. Todo ello, sin eludir, claro está, que ciertamente la prensa puede llegar a convertirse en el hilo conductor de la propaganda incitadora y justificadora de la violencia y la guerra.

\section{Asunto Dink vs. Turquía, de 14 de septiembre de 2010}

De noviembre de 2003, a febrero de 2004, el periodista turco, de origen armenio y editor en jefe del periódico semanal turco-armenio Agos, Furat Dink, publicó ocho artículos en los que expresaba su opinión sobre la identidad de los ciudadanos turcos de origen armenio. Y describía la obcecación de los armenios por el reconocimiento del genocidio perpetrado por el Imperio Otomano contra su pueblo. Demandando de las autoridades armenas mayores esfuerzos para fortalecer los lazos con la diáspora armena y llegando a apuntar que «la sangre purificada sustituirá a la sangre envenenada por el 'Turk'». ${ }^{69}$

Consecuencia de las publicaciones, el periodista fue denunciado en base al artículo 301 del Código penal turco que castiga la denigración de la identidad turca (Türklük). ${ }^{70}$ Siendo condenado a seis meses de prisión por la Corte Penal Şişli que sostuvo, en su resolución, que el público no podía esperar a leer todos los artículos para captar el significado real de la publicación. ${ }^{71}$

bierno de los Estados Unidos de América que calificaba al PKK como «organización terrorista extranjera» (foreign terrorist organisation), de conformidad con el artículo 219 de la US Immigration and Nationality Act. «The fact that such a period of time, more than 10 years, elapsed is in itself a factor which justifies a conclusion that the findings made in the order of the United Kingdom Home Secretary and in the FTO and SDGT designations were no longer sufficient for the purposes of determining whether the risk of the applicant's involvement in terrorist activities persisted at the time when the contested acts were adopted. The Council was therefore obliged to base the retention of the PKK on the lists at issue on more recent material, demonstrating that the risk of the PKK's involvement in terrorist activities persisted». Vid. STJUE, de 15 de noviembre de 2018 , T-316/14, 97.

${ }^{69}$ Vid. STEDH, de 14 de octubre de 2010, Dink vs. Turkey, párr. 16.

${ }^{70}$ Modificado por el Código penal del 12 de octubre de 2004, en el momento de los hechos tipificaba: «Se castiga con seis meses a tres años de prisión a cualquiera que denigre públicamente la identidad turca (Türklük) y a la República o la Gran Asamblea Nacional de Turquía. Será condenado a una pena de seis meses a dos años de prisión cualquier persona que denigre públicamente al Gobierno de la República de Turquía, a los órganos judiciales, a los militares o la seguridad del Estado. La pena se aumentará en una tercera parte cuando la identidad turca (Türklük) sea ofendió en el extranjero por un ciudadano turco; no constituyendo delito la expresión de opiniones críticas». Antiguo artículo 301 del Código penal turco.

71 Vid. STEDH, de 14 de octubre de 2010, Dink vs. Turkey, párr. 22. 
La sentencia fue ratificada por la sala novena del Tribunal Supremo, ello a pesar de que el Fiscal general consideró que las publicaciones estaban protegidas por la libertad de expresión. Finalmente, en casación, fueron archivadas las actuaciones tras el trágico asesinato de Frrat Dink del 19 de enero de 2007.

Las circunstancias del caso implicaban directamente a la policía turca ${ }^{72}$ pero, días antes de su asesinato, Dink había interpuesto una demanda contra Turquía ante el TEDH que fue continuada y extendida por sus familiares directos. Algunos de los hechos denunciados fueron: la omisión de las autoridades turcas de proteger la vida del periodista, la ineficacia de las investigaciones penales en torno al esclarecimiento de su asesinato y la defensa del derecho a la libertad de expresión e información en contra de una sentencia que le convirtió en el blanco de los extremistas nacionalistas.

Para resolver el asunto el TEDH tuvo que valorar que las fuerzas de seguridad turcas fueron realmente conscientes de la intensa hostilidad a la que estuvo sometido Frrat Dink por los círculos nacionalistas. Determinando que la amenaza de ser asesinado era real e inminente dado que, aunque el periodista nunca solicitó expresamente protección, él no podría saber que existía un plan para asesinarlo. Y, por el contrario, debían de ser las autoridades las que emprendieran medidas para salvaguardar su vida.

En base a lo anterior el TEDH determinó que resultó violado el artículo 2 del CEDH en su aspecto sustantivo. ${ }^{73}$ Registrando la misma violación del Convenio en lo referente a las deficiencias detectadas en el proceso de investigación de responsabilidades penales cometidas por las autoridades policiales.

${ }^{72}$ Diversas investigaciones policiales apuntaron que la gendarmería de Trabzon había actuado negligentemente o había fallado en su deber de prevenir la muerte. Un confidente afirmó haber avisado a dos suboficiales de la gendarmería del plan de asesinar a Dink y fue corroborado por los suboficiales que afirmaron haber transmitido todos los detalles a sus oficiales superiores; ordenándoles estos, negar haber recibido la información. En sus informes, el fiscal de Estambul advirtió de que uno de los jefes de policía de Trabzon había expresado abiertamente opiniones nacionalistas extremas y mostró su apoyo por los acusados del asesinato. Además, la fiscalía confirmó que, un año antes del asesinato de Dink, la policía de Trabzon habían informado oficialmente a la policía de Estambul de la probabilidad de que Firat Dink fuese asesinado. El proceso abierto en contra de la policía acabó siendo archivado al considerar el Tribunal Regional Administrativo de la Corte de Apelaciones de Estambul que la investigación había sido inadecuada. Al mismo tiempo, otra investigación se abrió contra los miembros de la gendarmería de Samsun que detuvieron al presunto sospechoso del asesinato. «While the suspected perpetrator was in police custody the persons concerned had had their photograph taken with the suspect, who was seen holding a Turkish flag: on the wall behind them were the words 'Our country is sacred - its future cannot be left to chance'». Ibídem, párr. 50.

${ }^{73}$ Ibídem, párrs. 66-75. 
En lo que respecta al derecho a la libertad de expresión, consideró el TEDH que, al condenar al periodista por los contenidos de sus artículos, éste quedó en el punto de mira de los nacionalistas extremos. Frente a ello las autoridades turcas, que habían sido informadas del complot para matarlo, no tomaron ningún tipo de medidas para protegerlo. ${ }^{74}$ Emprendiendo en cambio una injerencia en su derecho a la libertad de expresión. ${ }^{75}$

En la aplicación del escrutinio del test de Estrasburgo - si la injerencia perseguía un objetivo legítimo y si resultaba necesaria en una sociedad democrática - apreció la Corte europea que, del análisis de las publicaciones, el enfoque de la diáspora armenia para que los turcos reconozcan el genocidio de 1915 no podía calificarse como hate speech al modo que pretendieron los tribunales nacionales. ${ }^{76}$

Correspondiendo en cambio con una simple crítica al Estado, ${ }^{77}$ protegida por el artículo $10 \mathrm{CEDH}$, al estar prohibidas las restricciones a la libertad de expresión en el ámbito del debate político respecto a cuestiones de interés público. Enfatizando que los límites de la crítica aceptable son más amplios cuando se dirigen contra el Gobierno que cuando es dirigida contra un particular. Siendo, en suma, la cuestión del genocidio armenio un tema de interés y de preocupación pública.

En contradicción con la jurisprudencia surgida en asuntos concernientes a revisionismo histórico, apuntó el TEDH en Dink que la búsqueda de la verdad histórica es una parte integral de la libertad de expresión. ${ }^{78}$ Razón, esta

${ }^{74}$ En atención a Özgür Güdem, recuerda el TEDH, que el Estado tiene la obligación positiva de proteger el derecho a la libertad de expresión en contra de violaciones incluso de particulares. Vid. STEDH, de 16 de marzo de 2000, Özgür Güdem vs. Turkey, párrs. 42-46.

75 Vid. STEDH, de 14 de octubre de 2010, Dink vs. Turkey, párr. 108.

76 «La Cour relève en premier lieu que, comme l'a indiqué le procureur général près la Cour de cassation dans son pourvoi dans l'intérêt de la loi, l'examen de l'ensemble de la série d'articles dans laquelle le requérant avait utilisé l'expression contestée fait clairement apparaître que ce qu'il qualifiait de « poison » était la « perception du Turc » chez les Arméniens, ainsi que le caractère « obsessionnel » de la démarche de la diaspora arménienne visant à faire reconnaître par les Turcs que les événements de 1915 constituaient un génocide. Elle constate que Frrat Dink soutenait que cette obsession, qui faisait que les Arméniens se sentaient toujours « victimes », envenimait la vie des membres de la diaspora arménienne et les empêchait de développer leur identité sur des bases saines. La Cour en déduit, contrairement à la thèse du Gouvernement, que ces affirmations, qui ne visaient en rien « les Turcs », ne sauraient être assimilées à un discours de haine». Ibídem, párr. 128.

${ }_{77}$ Fórmula no compartida por los jueces Sajó y Tsotsoria quiénes adviertieron que el propio Tribunal Supremo turco consideró que el análisis de los «incidentes» en 1915 estaba protegido por la libertad de expresión. Ibídem, Votos concordantes de los jueces Sajó y Tsotsoria.

78 Ibídem, párr. 135. 
última, por la que la condena impuesta a Dink no revestía ninguna necesidad social imperiosa y - citando el asunto Özgür Güdem - fue contra la necesidad que tienen los Estados de crear entornos para el debate público sin miedo a la represión en los que la libertad de expresión debe de estar protegida incluso contra ataques hacia el propio Estado. ${ }^{79}$

Por todo ello, no se cumplieron las obligaciones que Turquía adquirió para proteger la libertad de expresión de Frrat Dink, por lo que, la sección décima del TEDH, compuesta por siete jueces y presidida por la juez belga Françoise Tulkens, consideró, de forma unánime, que se produjo una violación del artículo 10 del CEDH.

\subsection{El Estado, la protección de la prensa y la libertad de expresión}

Divergiendo del criterio general adoptado por la Corte europea, los jueces András Sajó (Hungría) y Nona Tsotsoria (Georgia) advirtieron de la inexistencia de obligaciones positivas derivadas del artículo 10 del CEDH.

De esta forma, sobre la base del asunto Dink, comprendieron que, en la planificación del crimen de Dink, no quedaba satisfecho que la condena y el asesinato estuviese relacionado y, menos, que fuesen parte de la violación de las obligaciones positivas del Estado para proteger a la prensa. En su tesis consideraban que la ausencia de protección no implicaba que el Estado deba de crear un entorno favorable para la participación en los debates públicos de todos los interesados.

Por otra parte sí que compartían la preocupación en lo concerniente a las amenazas y ataques a los que se ven sometidos los periodistas. Anticipando que de interpretarse un tipo de obligación positiva, en virtud del artículo 10 $\mathrm{CEDH}$, habría que tener cuidado de no caer en paternalismos. Dado que, protegiendo a la prensa, se terminaría restringiendo la propia libertad de expresión. Lo ejemplifican en la adopción de medidas de protección en beneficio de la prensa (en su mayoría la prensa progubernamental) y recuerdan que los abusos del Estado a menudo se cometen en nombre de obligaciones positivas.

Por ello, en el contexto del artículo $10 \mathrm{CEDH}$, de adoptarse algún tipo de medida, debería de quedar vinculada a un periodista específico que vea amenazada su vida; lo cual fusionaría las obligaciones positivas del Estado en virtud del artículo 2 del CEDH. ${ }^{80}$

79 Vid. STEDH, de 16 de marzo de 2000, Özgür Güdem vs. Turkey, párrs. 42-46; STEDH, de 14 de octubre de 2010, Dink vs. Turkey, párr. 106.

80 Acertadamente advierten también de que la mayor parte de las sentencias del TEDH sobre el artículo 10 exponen un análisis exhaustivo de las cuestiones de proporcionalidad, pero en algunos casos, como en este caso, este enfoque no es la mejor manera de 


\section{III.CONCLUSIÓN}

Constatada la misión de la prensa como public watchdog de la sociedad es preciso remachar la contribución que desempeña esta para el desarrollo de las sociedades democráticas. Su función queda constatada en tres vertientes: la de servicio público de la información, su misión de control de la actividad gubernamental y, en su caso, como instrumento de denuncia de vulneración de derechos.

Esta necesaria labor de defensa de los derechos humanos encuentra su bastión antagónico en el punto en el que los propios medios de comunicación pasan a ser el instrumento conductor y expansivo de la incitación a la violencia, la discriminación y la guerra. Un supuesto, este último, en el que obviamente se encontrará la connivencia gubernamental en caso de ser este el agente incitador. $\mathrm{O}$, por el contrario, tratará por todos los medios a su alcance de silenciar la propaganda que represente un clear and imminent danger constatado para el Estado y su población.

De entre las dos actividades mediáticas advertidas será, en la primera de ellas, donde las autoridades emplearan a fondo su Derecho penal del enemigo en un intento de silenciar aquellas teorías hirientes o que comprometan la actividad gubernamental.

En apariencia, Sürek, puede considerarse un asunto situado entre ambos supuestos. Por una parte, supuso un canal de denuncia de las atrocidades cometidas por el gobierno turco. Y, por otra, realizó una llamada tácita para tratar de desplazar al colonizador turco del Kurdistán.

Sin embargo, en su evidencia sustancial, no todo parece indicar que aquello fue un intento más de silenciamiento del enemigo mediante el empleo del Derecho. Principalmente porque un mensaje publicado en la sección de cartas del lector de un periódico, emitido en un único día, y por un autor desconocido, ni implicaba un riesgo real de incitación pública a la violencia o la guerra. Correspondiendo, en cambio, con un puro acto de desafección política.

proteger la libertad de expresión. Sobre la base circunstancial de este análisis es que cualquier persona que desee acogerse a la libertad de expresión garantizada por el artículo 10 está constantemente expuesta a la tentación de la autocensura. «Lorsqu'elle est soumise à l'arbitraire de restrictions juridiques aux contours trop larges ou trop flous, elle peut faire l'objet de poursuites, et en est réduit à espérer qu'une instance nationale ou la Cour jugera sa condamnation disproportionnée. Mais il lui est impossible de deviner à l'avance ce qui sera qualifié de " disproportionné ». Par exemple, une personne condamnée à une peine ou amende légère n'aura pas gain de cause pour des propos qui auraient bénéficié de la protection de l'article 10 dans d'autres affaires. Si elle est relaxée ou n'écope que d'une faible sanction, les poursuites judiciaires échapperont au radar de la Cour, alors même que ces poursuites, en soi, s'apparentent à un « châtiment», dans le sens d'un sérieux désagrément. D'où un phénomène d'autocensure, peu de personnes acceptant de s'exposer à une action en justice». Vid. STEDH, de 14 de octubre de 2010, Dink vs. Turkey, Votos concordantes de los jueces Sajó y Tsotsoria. 
De esta forma, como han venido reiterando los Relatores Especiales de la ONU, es preciso que los estados se abstengan del empleo del Derecho penal como instrumento de silenciamiento de los periodistas que tratan de denunciar públicamente las actuaciones del gobierno, del Estado en su conjunto o de terceros estados cuando estos actúan en contra de los derechos humanos.

Por todo ello advertimos que es preciso garantizar el pleno ejercicio de la libertad de expresión y de prensa. Y que esta se ha de realizar con unas con unas medidas de seguridad suficientes para permitir informar con independencia e imparcialidad proporcionándose a los profesionales de la información las medidas necesarias cuando pudiera quedar comprometida su seguridad. Todo ello sin llegar a caer en los paternalismos advertidos por los jueces Sajó y Tsotsoria en Dink; con el fin de evitar la protección unitaria y proliferación de la prensa pro-gubernamental.

Expuesta la teoría, nada de lo anterior resultaría viable cuando la fuente de promoción de la violencia se sitúa en los medios de comunicación. Ejemplos de la capacidad de llegar a la masa los encontramos en el caso del Ministerio de Propaganda de Goebbels y en Radio Télévision Libre des Mille Collines. ${ }^{81}$

Finalmente, el tipo se convertiría en especializado cuándo, existiendo una democracia, fuesen los medios los que, aprovechando su libertad de informar, promovieran el derrocamiento violento del gobierno democrático y terminen consolidando el ocultamiento de las graves vulneraciones de los derechos humanos que día tras día, ejecutó el régimen posterior. ${ }^{82}$

\section{BIBLIOGRAFÍA}

Álvarez NaKAGAWA, A., «Estándares sobre complicidad en el derecho internacional y la responsabilidad de los periodistas en graves violaciones a los derechos huma-

81 «Con mucha mayor rapidez que en la prensa, el estado nacional-socialista, por obra de Goebbels, logró hacerse con el control y dirección de la radiodifusión alemana. La intervención de la radio producía (por sus conocidas características) un impacto masivo en el subconsciente del pueblo alemán. El estilo, la organización, las ideas, su ritmo y la aplicación de fórmulas totalmente desconocidas en aquel entonces colocaron a la radio en un terreno trascendente de auténtico y real poder». Vid. Técnicas de publicidad persuasiva, Instituto Nacional de Publicidad, Madrid, 1971, p. 260

${ }^{82}$ Un buen ejemplo cercano lo encontramos en toda la propaganda emitida por los sublevados en contra del gobierno democrático de la Segunda República española. Y, del mismo modo, en el Chile de Salvador Allende, Vid. ÁLVAREZ NAKAGAWA, A., «Estándares sobre complicidad en el derecho internacional y la responsabilidad de los periodistas en graves violaciones a los derechos humanos», ANITUA, G. I., ÁLVAREZ NAKAGAWA, A., GAITÁN, M. (Edits.), Los juicios por crímenes de lesa humanidad: enseñanzas jurídico penales, Buenos Aires, Ediciones Didot, 2014, p.. 175. 
nos», Anitua, G. I., Álvarez Nakagawa, A., Gaitán, M. (Edits.), Los juicios por crímenes de lesa humanidad: enseñanzas jurídico penales, Buenos Aires, Ediciones Didot, 2014, pp. 175 y ss.

BUTTURINI. D., «L' informazione tra diritto individuale di libertà politico-economica e funzione di servizio pubblico», AA.VV., Studi in onore di Maurizio Pedrazza Gorlero, Edizione Scientifiche Italiane, Vol. II. La libertà di informazione e la democrazia constituzionale, 2014.

CAPAldi, N., Censura y libertad de expresión, Buenos Aires, Ediciones Libera, 1969.

De LuCA, A. J., Libertad de prensa y delitos contra el honor: delitos contra el honor cometidos a través de la prensa, Buenos Aires, Ad-Hoc, 2006.

Fiss, O., Libertad de Expresión y Estructura Social, Malem Seña, J. (Trad.), México D.F., Distribuciones Fontamara, S.A., 1997.

ForD, H., El Judio Internacional. Un problema del mundo, Resistencia, Ediciones Chaco, 1975.

Galeano, E., La comunicación desigual, Conferencia en la Unidad Xochimilco, México, 1995.

Gordon, G. S., «Hate Speech and Persecution: A Contextual Approach», Vanderbilt Journal of Transnational Law, Vol. 46, núm. 2, 2013.

Gunes, C., The Kurdish National Movement in Turkey. From protest to resistance, Oxon, Routledge, 2012.

Madison, J., The debates in the several state conventions, on the adoption of the Federal Constitution, Washington, Jonathan Elliot, Vol. IV, 1836, pp. 569-570.

Marcuse, H., «La tolerancia represiva», CAPALDI, N., Censura y libertad de expresión, Buenos Aires, Ediciones Libera, 1969.

Ovey. C., y White, R. C. A, Jacobs and White: The European Convention on Human Rights, Fourth Edition, Oxford, Oxford University Press Inc., 2006

Rowbotтom, J., «Extreme Speech and Democratic Functions of the Mass Media», Hare, I., Weinstein (Edits.), J., Extreme speech and democracy, Oxford University Press, 2009.

Serrano, P., Medios violentos. Palabras e imágenes para el odio y la guerra, El Viejo Topo, 2008.

Zaffaroni, E.R., Ferrajoli, L., Torres, S. G., Basilico, R. A., La emergencia del miedo, Buenos Aires, Ediar, 2012. 


\title{
RADICALIZACIÓN MEDIÁTICA Y ABUSO DEL DERECHO EN LA DOCTRINA DEL TRIBUNAL EUROPEO DE DERECHOS HUMANOS
}

\section{Radicalization of the Media and Abuse of the law in the Doctrine of the European Court of Human Rights}

\author{
David Martín Herrera \\ Profesor de Derecho Constitucional \\ Departamento de Servicios Sociales y Fundamento Histórico-Jurídicos \\ Universidad Nacional de Educación a Distancia
}

http://dx.doi.org/10.18543/ed-68(1)-2020pp397-424

\section{Copyright}

Estudios de Deusto es una revista de acceso abierto, lo que significa que es de libre acceso en su integridad. Se permite su lectura, la búsqueda, descarga, distribución y reutilización legal en cualquier tipo de soporte sólo para fines no comerciales, sin la previa autorización del editor o el autor, siempre que la obra original sea debidamente citada y cualquier cambio en el original esté claramente indicado

Estudios de Deusto is an Open Access journal which means that it is free for full access, reading, search, download, distribution, and lawful reuse in any medium only for non-commercial purposes, without prior permission from the Publisher or the author; provided the original work is properly cited and any changes to the original are clearly indicated. 